\title{
Pavimentação Asfáltica: Contribuição no Aquecimento de Áreas Urbanas
}

\section{Asphalt Paving: Contribution for Urban Heating Areas}

\author{
1'Ivan Júlio Apolônio Callejas (ivancallejas@ig.com.br) \\ 2Luciane Cleonice Durante(luciane.durante@hotmail.com) \\ ${ }^{3}$ Karyna de Andrade Carvalho Rosseti \\ ${ }^{1}$ Professor do PPGEEA, Laboratório de Conforto / UFMT. \\ ${ }^{2}$ Professora do PPGEEA, Laboratório de Conforto / UFMT. \\ 3Professora no Departamento de Arquitetura da Universidade Federal de Mato Grosso (UFMT)
}

Recebido e aceito em: maio $2015 \quad$ Publicado em: junho 2015

RESUMO: O material mais utilizado para pavimentação do meio urbano no Brasil é o pavimento asfáltico. Pelas suas características termofísicas, este pavimento contribui para o aumento das temperaturas ambientais nos locais em que é aplicado. O presente artigo tem por objetivo avaliar o comportamento térmico de pavimento asfáltico ao longo de um ciclo diário, em região de clima tropical, com vistas à sua contribuição para o aquecimento de áreas urbanas. Por meio de medições de albedo, temperatura do ar, temperaturas superficiais externas e internas do pavimento e de fluxo de calor, verificou-se que albedo se enquadrou dentro dos limites propostos na literatura $(0,16)$, a temperatura superficial externa e interna foram superiores a $50^{\circ} \mathrm{C}$ e que o fluxo de calor armazenado atingiu 244,73 $\mathrm{Wm}^{-2}$, superiores aos fluxos do solo desprovido de vegetação e dos solos pavimentados por concreto. Desta forma, como os fluxos de calor armazenado neste pavimento são elevados, pode-se afirmar que o mesmo é um dos grandes responsáveis pelo processo de formação das ilhas de calor nas cidades.

Palavras-chave: pavimentos, fluxo de calor, albedo.

ABSTRACT: The most commonly used material for paving urban environment in Brazil is the asphalt paving. By their thermophysical characteristics, this pavement contributes to increased environmental temperatures in places where it is applied. This paper aims to evaluate the thermal behavior of asphalt paving daily in tropical climate region, to point of view to their contribution to the heating of urban areas. By measurements of albedo, air temperature, external and internal surface temperatures and heat stored inside of the pavement, it was verified that albedo value was inside the limits of scientific literature proposal $(0,16)$, external and internal temperature were superior than $50^{\circ} \mathrm{C}$ and energy stored inside the pavement was $244.73 \mathrm{~W} \mathrm{~m}^{-2}$, superior of heating fluxes inside bare soil and concrete pavement. Thus, how heating fluxes stored inside in this pavement are high, it can be stated that the asphalt pavement is one of the responsible for the heat islands formation process in cities.

Key-words: dry asphalt, heat flux, albedo.

\section{INTRODUÇÃO}

Nas áreas com elevada densidade de áreas construída e pavimentada e baixa densidade de áreas verdes, como as que ocorrem em centros urbanos, nota-se elevação da temperatura do ar local. Este fenômeno é conhecido como ilha de calor, caraterizado pela elevação das temperaturas do ar e das superfícies do meio urbano em relação às do entorno rural próximo. A presença $\mathrm{e} \quad \mathrm{O}$ poluição do ar, dentre outros (OKE, 1987). desenvolvimento das ilhas de calor urbanas são negativos para o meio ambiente, pois provocam alterações na umidade do ar, precipitação e ventos e intensificam $\mathrm{o}$ fenômeno conhecido como aquecimento global (GARTLAND, 2010), além de trazer como consequência desconforto térmico, problemas de saúde, elevação do consumo de energia para refrigeração dos ambientes, maior Áreas pavimentadas contribuem para a formação das ilhas de calor, pois se 
aquecem com a incidência de radiação solar, armazenam energia térmica e liberam calor para o ambiente ao seu redor, principalmente no período noturno, através de fluxo de calor sensível e radiação infravermelha (ANANDAKUMAR, 1999). Os materiais de construção, tipicamente utilizados na constituição do meio urbano, têm maior capacidade de retenção de energia do que os constituintes do meio rural. Dessa forma, o meio urbano possui maior capacidade de armazenamento de energia do que meio rural (OKE, 1987).

O balanço de radiação para uma determinada superfície corresponde à soma de toda energia radiante recebida e perdida, que dependem de fatores físicos e termodinâmicos associados ao sistema superfície-atmosfera, tais como albedo, emissividade rugosidade da superfície, capacidade, condutibilidade, difusividade e efusividade térmica dos meios.
O albedo é uma medida adimensional correspondente à percentagem da radiação solar incidente que é refletida pela superfície, calculado a partir de dados de radiação solar global e a emissividade é a capacidade dos materiais emitirem a radiação absorvida. A difusividade é um indicador importante para expressar a capacidade que um material tem em transmitir variação de temperatura, ou seja, a velocidade com que o calor se propaga no seu seio, enquanto a efusividade térmica caracteriza a rapidez com que um material absorve ou libera calor (YANNAS e MALDONADO, 1995). Na Tabela 1, apresenta-se o albedo e a emissividade para solo exposto, concreto e pavimento asfáltico, sendo que o resultado do balanço energético das superfícies revestidas por asfalto ou concreto difere das superfícies naturais não pavimentadas, devido às diferentes propriedades físicas e termodinâmicas.

Tabela 1. Propriedades termo radiantes do solo, concreto e pavimento asfáltico.

\begin{tabular}{llllll}
$\begin{array}{l}\text { Tipo de } \\
\text { Superfície }\end{array}$ & Albedo & Emissividade & $\begin{array}{l}\text { Condutibilidad } \\
\mathbf{e}\end{array}$ & $\begin{array}{l}\text { Difusividade } \\
(\mathbf{m} 2 \mathbf{s}-\mathbf{1} \times \mathbf{~ 1 0 - 6})\end{array}$ & $\begin{array}{l}\text { Efusividade } \\
(\mathbf{J} \text { m-2s-1/2 K- } \\
\mathbf{1})\end{array}$ \\
\hline $\begin{array}{l}\text { Solos } \\
\text { (secos) }\end{array}$ & $0,05-0,40$ & $0,90-0,94$ & $0,06-0,3$ & $0,10-0,24$ & $190-620$ \\
$\begin{array}{l}\text { Concreto } \\
\text { denso* }\end{array}$ & $0,10-0,35$ & $0,90-0,96$ & $1,28-1,74$ & $0,63-0,72$ & $1604-2048$ \\
$\begin{array}{l}\text { Pavimento } \\
\text { Asfáltico** }\end{array}$ & $0,05-0,20$ & 0,95 & $1,39-1,56$ & $0,45-0,52$ & $1689-1957$ \\
\hline
\end{tabular}

Adaptado de Oke (1987), * Frota e Schiffer (2003), ** Hellmann (2008).

Algumas estratégias podem ser utilizadas com objetivo de atenuar os efeitos das ilhas de calor, principalmente nas cidades de climas tropicais, tais como aumento e manutenção das áreas verdes urbanas, diminuição da poluição do ar e substituição de materiais de cores escuras, de alta absorção de energia e elevada condutividade/ efusividade por materiais claros de baixa absorção e menor condutividade/ efusividade térmica (GARTLAND, 2010).
Diante das modificações ambientais que os materiais artificiais produzem no meio, o presente trabalho objetivou descrever o comportamento das temperaturas superficiais internas $\mathrm{e}$ externas de superfícies com pavimentação asfáltica e o fluxo de calor armazenado ao longo de um ciclo diário na estação chuvosa, em região de clima tropical continental, visando principalmente evidenciar os impactos de suas aplicações no meio urbano. 


\section{MATERIAIS E MÉTODOS}

\section{Local da Pesquisa}

Esta pesquisa foi realizada em uma área urbana na cidade de Cuiabá/MT, em área de estacionamento, nas proximidades da Faculdade de Arquitetura, Engenharia e Tecnologia (FAET), no campus da UFMT, em cujo solo foi aplicado pavimentação asfáltica há mais de 30 anos (Figura 1).

Figura 1 - Local do experimento.

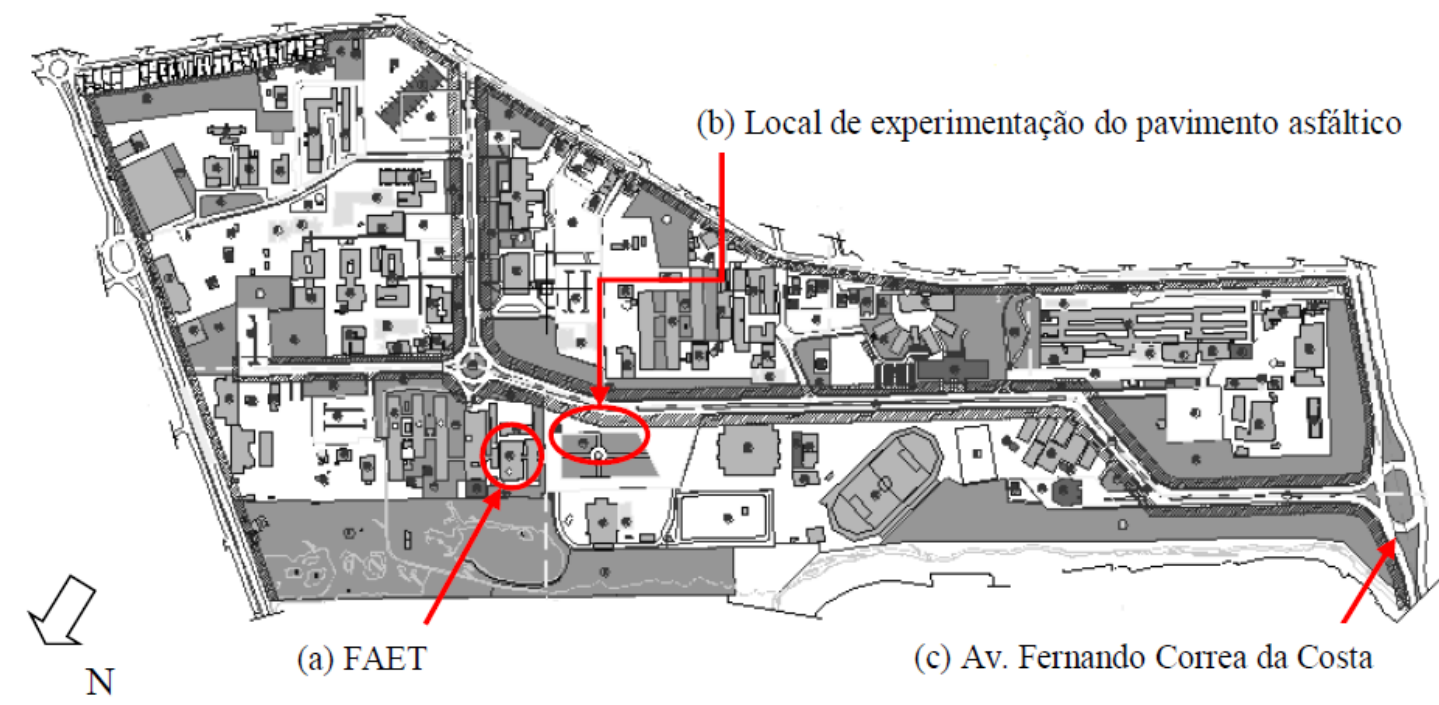

Equipamentos e Procedimentos de Medição

As variáveis da pesquisa consistem de radiação global, refletida, temperatura do ar, temperaturas das superfícies externa, interna e fluxo de calor no pavimento asfáltico. A radiação global incidente foi coletada em estação meteorológica instalada a 50 metros do local da instrumentação, junto ao bloco da FAET. O albedo foi medido através do método do piranômetro invertido (Figura 2), instalado junto ao abrigo meteorológico. Utilizaram-se sensores de temperatura para a medição de temperatura superficial interna e externa e abrigo meteorológico (Figura 3).
Figura 2 - Representação esquemática da instalação de piranômetro invertido.
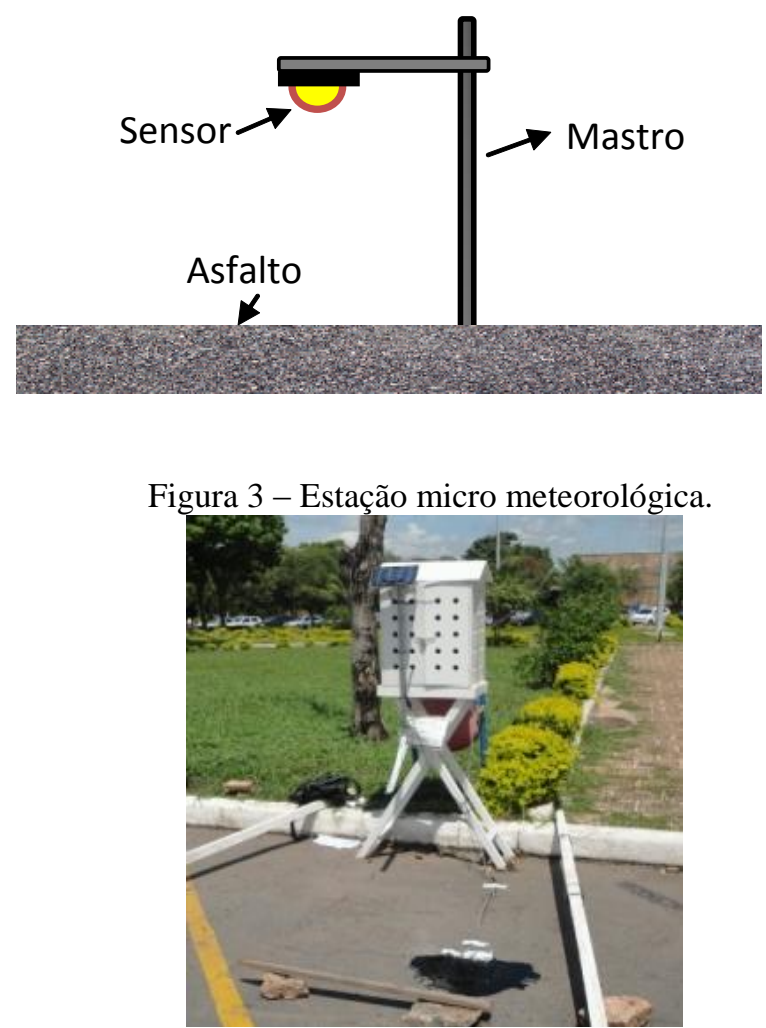
$\mathrm{Na}$ medição do fluxo de calor que se propaga através do pavimento asfáltico foi utilizado um termo fluxímetro marca Hukseflux, modelo HFP01 (fluxímetro de calor). Para instalação do fluxímetro de calor foi realizado recorte no pavimento asfáltico (Figura 4), retirando uma porção de cerca de $20 \mathrm{~cm}$ de largura e $20 \mathrm{~cm}$ de comprimento, com espessura de aproximadamente $5 \mathrm{~cm}$ (Figura 5). Juntamente com o termo fluxímetro foi instalado sensor de

Figura 4 - Corte no asfalto.

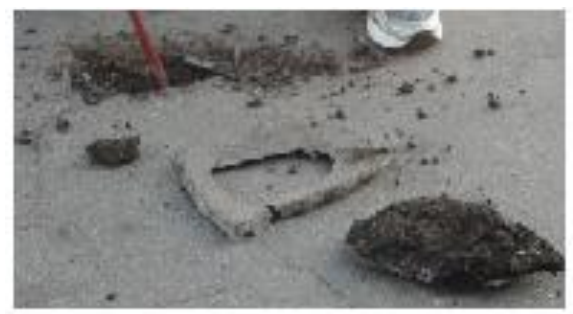

Figura 6 - Termo fluxímetro/ sensor de temperatura superficial da face interna do pavimento asfáltico.

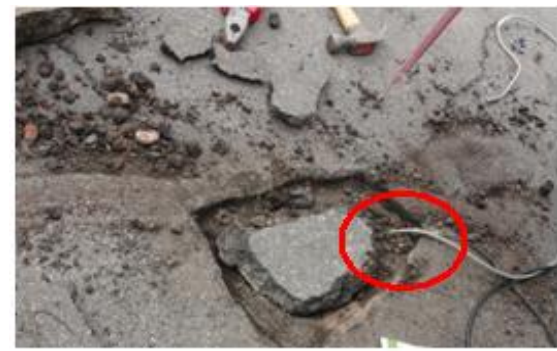

Para o registro da temperatura superficial externa, foi instalado sensor de temperatura sobre a superfície. Com a finalidade de minimizar a influência incidência de radiação solar direta no sensor, o mesmo foi recoberto com poliestireno envolvido em papel alumínio (Figura 8). temperatura superficial na face interna do pavimento asfáltico (Figura 6). Após a instalação dos equipamentos, o pavimento recortado foi novamente disposto no local. Os vãos remanescentes foram preenchidos com rejunte e emulsão asfáltica foi aplicada área recortada com objetivo de impermeabiliza, impedindo que as precipitações pluviométricas interferissem nas medições (Figura 7).

Figura 5 - Porção de pavimento recortada de $20 \times 20 \times 5 \mathrm{~cm}$.

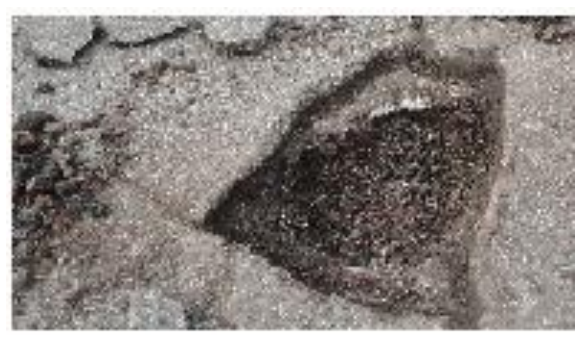

Figura 6 - Porção recortada recolocada.

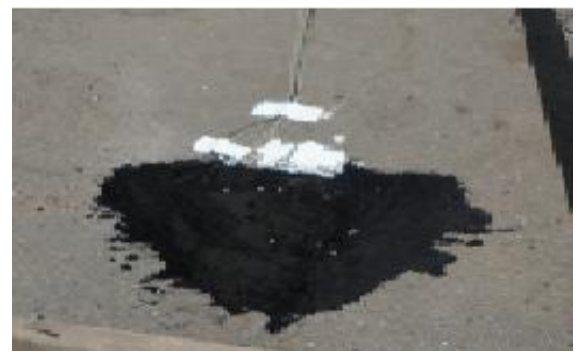

Os sensores foram acoplados ao registrador de dados automático Onsetcomp U12-13 e o termofluxímetro a um amplificador de tensão conectado ao registrador de dados automáticos Onsetcomp U30, dispostos no interior do abrigo meteorológico (Figura 9). 
Figura 8 - Sensor de temperatura superficial e proteção contra radiação solar direta

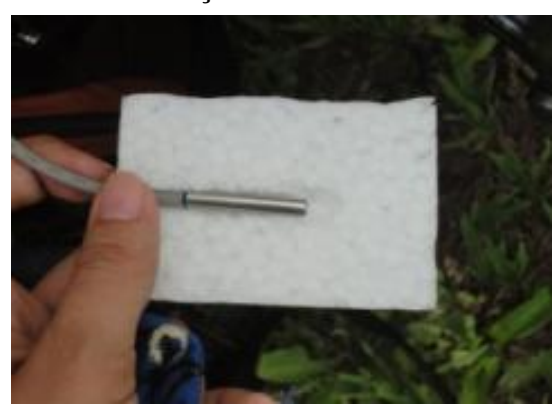

Período de Experimentação

As medições foram realizadas durante seis dias consecutivos, de 12 a 16 de dezembro de 2012. Durante este período, observou-se precipitação pluviométrica nos dias 13, 14 e 15 . Por este motivo, apenas os dias 12 e 16 foram considerados na análise.

Os dados produzidos pelos sinais e/ou pulsos elétricos dos sensores

\section{DISCUSSÃO DOS RESULTADOS}

Nota-se que o albedo sofreu variação durante o período diurno, com valor máximo de 0,21 às $9 \mathrm{~h} 30$ min e mínimo de 0,09 às $17 \mathrm{~h}$ (Figura 10). $\mathrm{O}$ valor médio observado foi de 0,16 , superior
Figura 9 - Equipamentos no interior do abrigo meteorológico

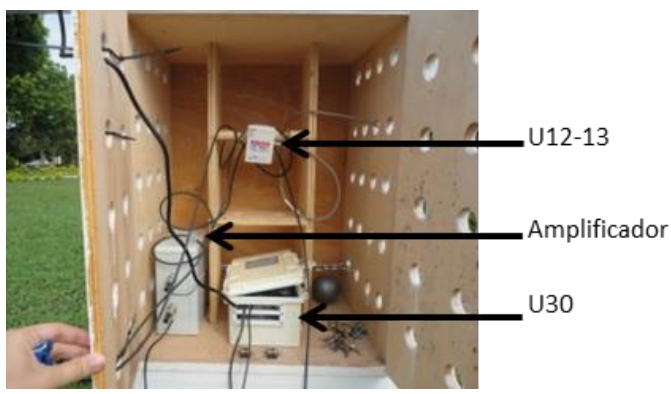

meteorológicos foram processados e armazenados nos registradores automático da Marca OnsetComp Modelo U12-13 e U30, com médias a cada 5 minutos, sendo posteriormente reprocessados para intervalos de 60 minutos para a avaliação da média temperatura horária do albedo, temperatura superficial externa e interna e fluxo de calor armazenado.

ao observado em Asaeda et al. (1996) que foi de 0,10 , provavelmente por tratar de pavimento asfáltico antigo (mais de 30 anos), cuja a tendência é de elevação do albedo com o tempo.

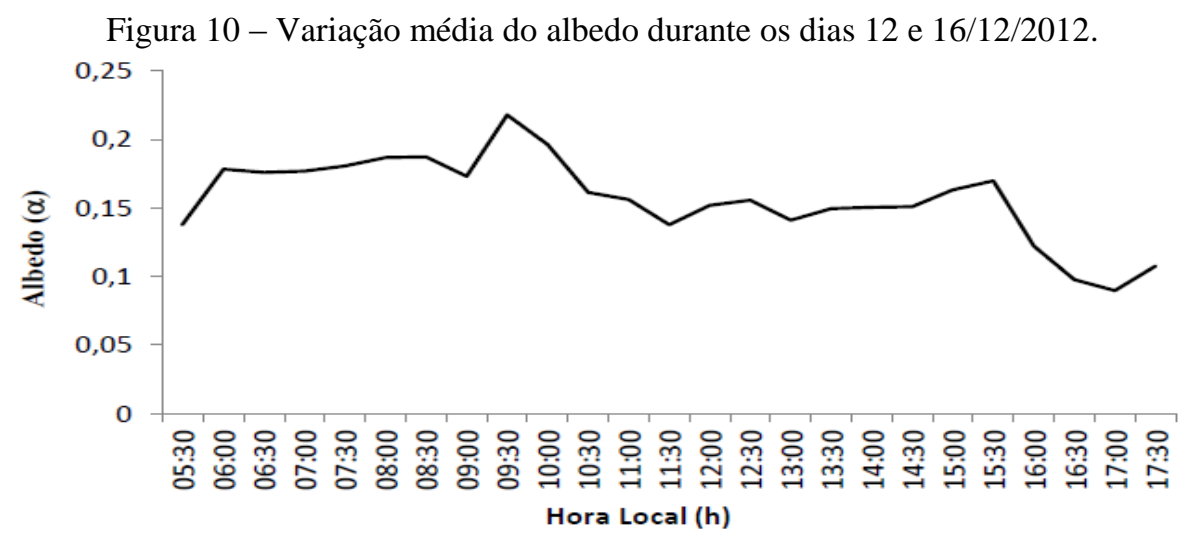

As temperaturas superficiais máximas externas e internas foram de $50,92^{\circ} \mathrm{C}$ às $12 \mathrm{~h} 30 \mathrm{~min}$ e $50,17^{\circ} \mathrm{C}$ às $13 \mathrm{~h}$, respectivamente. As mínimas alcançaram $29,91^{\circ} \mathrm{C}$ às $5 \mathrm{~h}$ e $31,92^{\circ} \mathrm{C}$ às 5h30min, respectivamente. $\mathrm{O}$ amortecimento térmico foi de $0,75^{\circ} \mathrm{C}$ e o atraso térmico de $0,5 \mathrm{~h}$. Os valores médios da temperatura do ar, superficial externa e interna foram de $29,11^{\circ} \mathrm{C}$, $37,80^{\circ} \mathrm{C}$ e $39,19^{\circ} \mathrm{C}$, respectivamente. Verifica-se que a temperatura superficial é superior a do ar durante todo o período diurno e noturno, o que 
contribui para aquecer a baixa atmosfera, diferentemente do que acontece nas superfícies com solo exposto ou vegetando, onde a tendência é, durante a noite, manter a temperatura superficial inferior a do ar. Exceção a este comportamento se verifica no período do inverno, onde se pode verificar que temperatura do ar em alguns períodos pode ser superior ao da superfície do solo. No estudo realizado por Anandakumar (1999), as temperaturas chegaram a alcançar máxima externa de $44^{\circ} \mathrm{C}$ e interna de $38^{\circ} \mathrm{C}$ às $16 \mathrm{~h} 30 \mathrm{~min}$. Em Asaeda et al. (1996), as temperaturas foram superiores a $60^{\circ} \mathrm{C}$ às $14 \mathrm{~h}$, sendo que as temperaturas do concreto convencional e solo exposto não ultrapassaram $39^{\circ} \mathrm{C} \mathrm{e}$ $38^{\circ} \mathrm{C}$, respectivamente. Em estudo sobre pavimento de concreto convencional e poroso nas proximidades do experimento realizado neste trabalho, Violante (2013) verificou em dezembro de 2012, temperaturas médias máximas de $38,40^{\circ} \mathrm{C}$, às $13 \mathrm{~h}$. Assim, os resultados demonstram que o pavimento asfáltico é um dos materiais que apresentam as mais altas temperaturas superficiais dentro do meio urbano, contribuindo de forma decisiva para o aquecimento do ar nestas áreas.

Observa-se que o os valores da temperatura superficial externa foram maiores aos da interna no período de $8 \mathrm{~h}$ às 13h30min. Justifica-se este comportamento pela baixa efusividade e elevada condutibilidade térmica do pavimento asfáltico constatada pela proximidade entre os valores da temperatura superficial externa e interna medidos, o que implica em dizer que a energia térmica é conduzida de forma rápida para o interior do material. Das 13h 30min até o final da madrugada, a temperatura superficial interna mantémse superior à externa devido à propriedade da efusividade que é elevada no pavimento asfáltico (absorvendo e retendo muito energia), bem como devido à difusividade que é baixa, dificultando o seu resfriamento, o que também explica durante este período a temperatura superficial média interna superior à externa.

Figura 11 - Temperatura média do ar e temperatura superficial externa e interna.

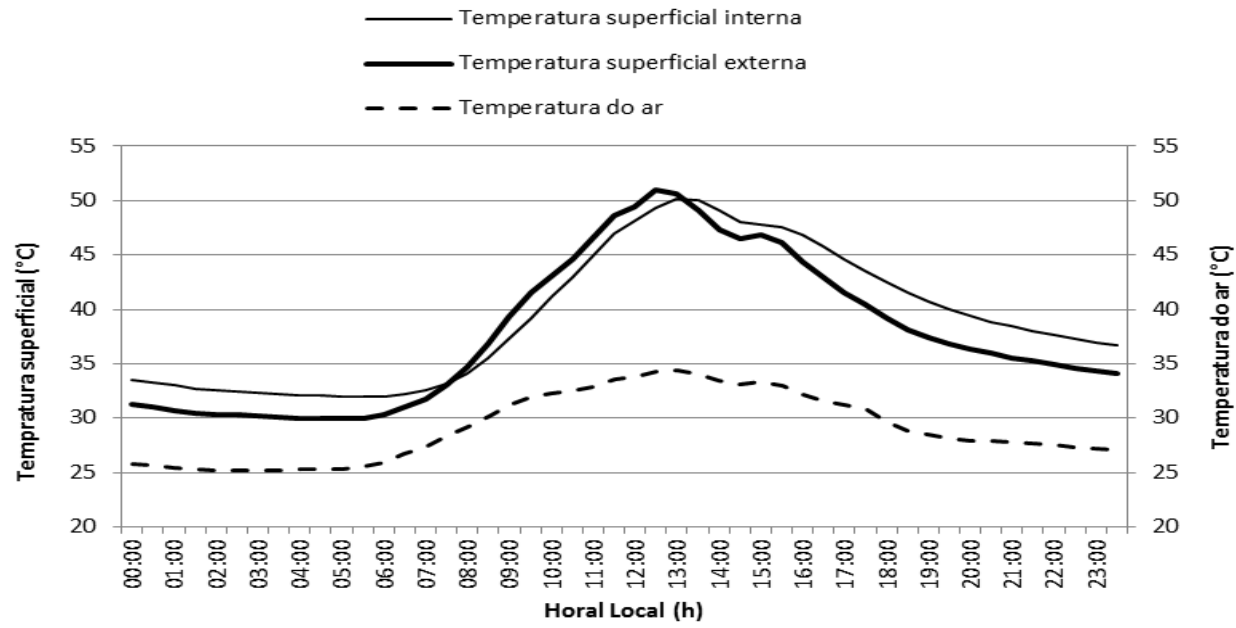

A radiação solar global e o fluxo de calor máximo foram de 995,74 e 244,73 $\mathrm{Wm}^{-2}$ às $11 \mathrm{~h} 30 \mathrm{~min}$, respectivamente. $\mathrm{O}$ resultado do fluxo armazenado se aproxima do valor encontrado por Anandakumar (1999) que determinou cerca de $300 \mathrm{~W} \mathrm{~m}^{-2}$ e em Asaeda et al. (1996), $250 \mathrm{Wm}^{-2}, 180 \mathrm{Wm}^{-2}$ e $160 \mathrm{~W}$ $\mathrm{m}^{-2}$ para o pavimento asfáltico, de concreto e solo descoberto. Em estudo realizado na região da Baixada Cuiabana, em região desprovida de 
qualquer superfície artificial (em área de cerrado desmatado), Rodrigues (2011) determinou fluxos de calor com valor máximo de aproximadamente $100 \mathrm{Wm}^{-}$ 2. Callejas (2012) estimou o calor armazenado dentro do dossel urbano pelo Modelo Objetivo de Histerese (OHM) proposto por Grimmond et al. (1991) em área com elevada taxa de impermeabilização $(73 \%)$, região central da cidade de Cuiabá e verificou que o valor máximo do fluxo ocorreu às 11h30min, com intensidade de 134,90 $\mathrm{Wm}^{-2}$. É importante destacar que no Modelo Objetivo de Histerese (OHM), o calor é estimado a partir das frações de áreas dos diversos tipos de superfícies existentes dentro do meio urbano, inclusive do pavimento asfáltico. Desta forma, diante dos elevados fluxos de calor armazenado no seu interior, pode-se afirmar que o pavimento asfáltico é um dos grandes responsáveis pelo processo de formação das ilhas de calor nas cidades. Violante (2013) em estudo comparativo entre pavimento de concreto convencional e permeável (drenante) estimou fluxos de calor armazenado máximos de 111,76 $\mathrm{W} / \mathrm{m}^{2}$ no revestimento convencional e de $85,68 \mathrm{~W} / \mathrm{m}^{2}$ nos pavimentos permeáveis, o que ratifica os estudos de Asaeda et al. (1996) que determinou os maiores valores nos pavimentos asfálticos.

Figura 12 - Valores médios da radiação solar global e fluxo de calor armazenado.

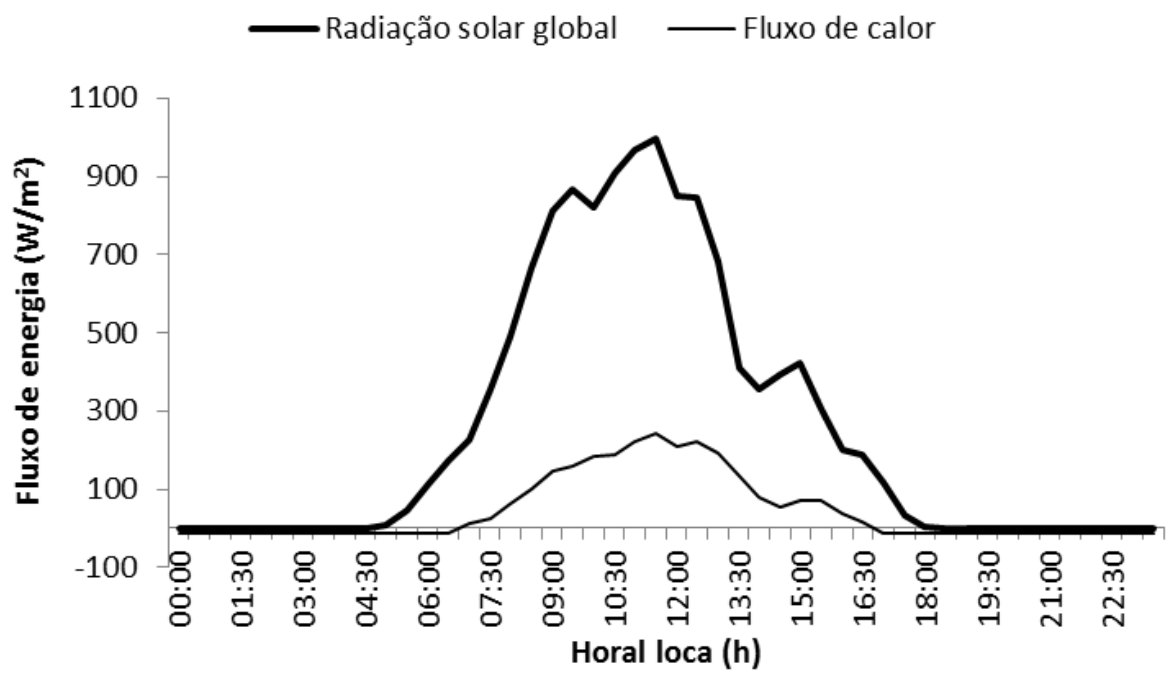

Isso ocorre porque, com o aumento da radiação solar, a energia é armazenada no pavimento asfáltico, sendo também liberada para $\mathrm{o}$ ar por meio de convecção e radiação. Desde o inicio da manhã até o inicio da tarde, a convecção e a irradiação não é suficiente para resfriar o pavimento e a energia acaba sendo então estocada no pavimento. A partir do início da tarde, à medida que a energia solar declina, o asfalto consegue gradativamente liberar $\mathrm{o}$ calor armazenado, por convecção e radiação, sendo, portanto resfriado. Devido à sua impermeabilização (ausência de água no pavimento), quase toda a energia é armazenada ou dissipada na forma de calor sensível, contribuindo desta forma para a elevação da temperatura do ar no meio urbano. 


\section{CONCLUSÕES}

$\mathrm{O}$ valor médio do albedo do pavimento asfáltico foi de 0,16 , o que se enquadra nos limites citados na literatura $\mathrm{e}$ classificado como de baixo valor, o que contribui para maior disponibilidade de energia no meio, aumentando a energia estocada e a temperatura superficial das superfícies destes materiais.

Verificou-se que as temperaturas superficiais externas mantiveram-se elevadas durante o período diurno, o que contribui para a elevação da temperatura do ar no meio urbano. Notou-se diferença entre as temperaturas superficiais externas e internas de $0,75^{\circ} \mathrm{C}$ e atraso térmico de $0,5 \mathrm{~h}, \quad$ o que confirma a elevada condutibilidade e efusividade térmica deste material. A temperatura superficial se mantém superior à temperatura do ar, aquecendo a atmosfera em grande parte do período vespertino e noturno. Isto acontece devido à elevada efusividade térmica do material se comparada à dos solos descobertos e vegetados, que se resfriam mais rapidamente. $\mathrm{O}$ comportamento de elevada absorção de calor fica comprovado pelos elevados valores de temperatura superficial registrados na face superficial interna, localizada a $5 \mathrm{~cm}$ do nível do solo.

Pelos resultados, tem-se que o asfalto é um material que contribui consideravelmente para o aquecimento das regiões urbanas, ajudando na formação de ilhas de calor e aquecimento global. Portanto, o uso de materiais com melhores características termofísicas nos grandes centros urbanos poderia reduzir problemas ambientais e também melhorar o conforto térmico da população que vive em regiões urbanas, principalmente em regiões de clima quente, como é o caso da cidade de Cuiabá/MT.

\section{Agradecimentos}

Agradecemos à Fundação de Amparo à Pesquisa de Mato Grosso (FAPEMAT) pelo suporte financeiro à esta pesquisa.

\section{REFERÊNCIAS BIBLIOGRÁFICAS}

ANANDAKUMAR, K. A study on the partition of net radiation into heat fluxes on a dry asphalt surface. Atmospheric Environment, v.33, p.3911-3918, 1999.

ASAEDA, T.; CA, V. T. Heat storage of pavement and its effect on the lower atmosphere.

Atmospheric Enviromnent, v. 30, n. 3, p. 413-427, 1996.

CALlEJAS, I. J. A. Avaliação temporal do balanço de energia em ambientes urbanos na cidade de Cuiabá-MT. Cuiabá, 2012. 265f. Tese (Doutorado), Programa de Pósgraduação em Física Ambiental, Universidade Federal de Mato Grosso, Cuiabá, 2012.

FROTA, A. B.; SHIFFER, S. R. Manual de Conforto Térmico. São Paulo: Ed. Studio Nobel, 2003.

GARTLAND, L. Ilhas de calor: como mitigar zonas de calor em áreas urbanas. São Paulo: Oficina de Textos, 2010.

GRIMMOND, C. S. B.; CLEUGH, H. A. and OKE, T. R. An objective urban heat storage model and its comparison with other schemes. Atmospheric Environment, v.25, n.3, p.311-326, 1991.

HELLMANN, L. Determinação de propriedades térmicas de materiais de pavimentação. Dissertação (mestrado), Programa de PósGraduação em Modelagem Matemática, Universidade Regional do Noroeste do 
Estado do Rio Grande do Sul, Ijuí, 2008.

OKE, T. R. Boundary Layer Climates. 2. ed. Routledge. New York, p. 435. 1987.

RODRIGUES, T.R. Variabilidade interanual da sazonalidade de fluxos de energia e matéria em área de Cerrado na Baixada Cuiabana. 2011. 85p. Dissertação (Mestrado em Física Ambiental), Instituto de Física, Universidade Federal de Mato Grosso, Cuiabá, 2011.

VIOLANTE, F. Estudo comparativo de desempenho térmico entre revestimento convencional e permeável. Cuiabá, 2013. 50f. Monografia (Conclusão de curso), Faculdade de Arquitetura, Engenharia e Tecnologia, Departamento de Engenharia Civil, Universidade Federal de Mato Grosso, Cuiabá, 2013.

YANNAS, S., MALDONADO, E., eds. PASCOOL handbook - Designing for summer comfort. Architectural Association Graduate School, Londres, 1995. Cap. 4: Thermal Inertia. 